\title{
A global analysis of SNX27-retromer assembly and cargo specificity reveals a function in glucose and metal ion transport
}

Florian Steinberg, Matthew Gallon, Mark Winfield, Elaine C. Thomas, Amanda J. Bell, Kate J. Heesom, Jeremy M. Tavaré and Peter J. Cullen

Nat. Cell Biol. 15, 461-471 (2013); published online 7 April 2013; corrected after print 4 July 2014

In the version of this Article originally published, an error in the journal production process led to the wrong image being used for 'SNX27KD' in Fig. 4b. The correct image is shown below and is corrected in all online versions of the Article.
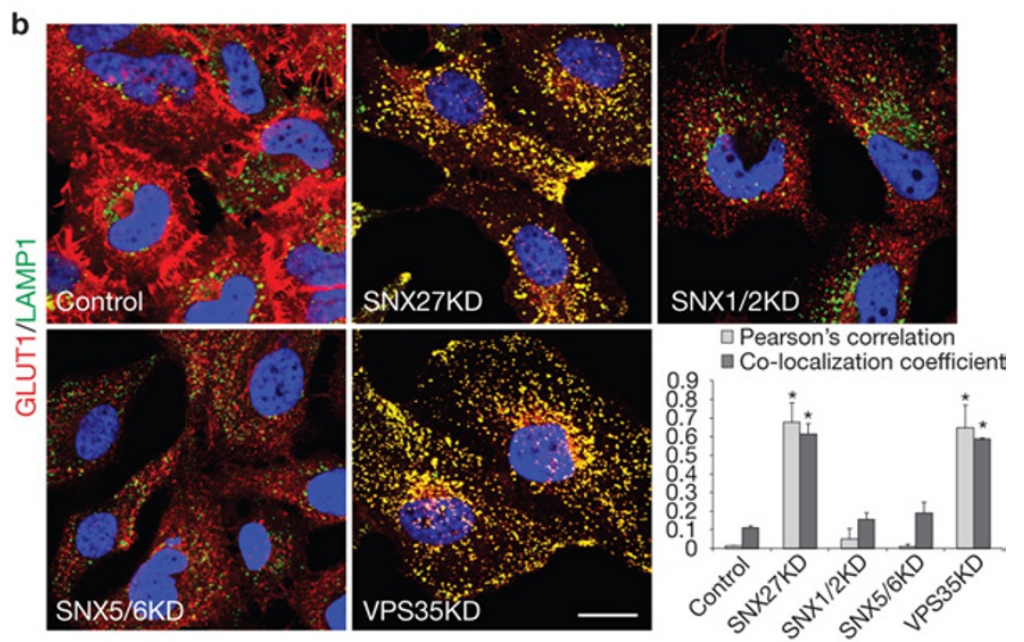

\section{Lipidation of the LC3/GABARAP family of autophagy proteins relies on a membrane-curvature-sensing domain in Atg3}

Sangeeta Nath, Julia Dancourt, Vladimir Shteyn, Gabriella Puente,Wendy M. Fong, Shanta Nag, Joerg Bewersdorf, Ai Yamamoto, Bruno Antonny and Thomas J. Melia

Nat. Cell Biol. 16, 415-424 (2014); published online 20 April 2014; corrected after print 4 July 2014

In all previously published versions of this Article, the graph in Fig. 5c was incorrect; the correct graph is shown below. This error has now been corrected in all online versions of the Article.

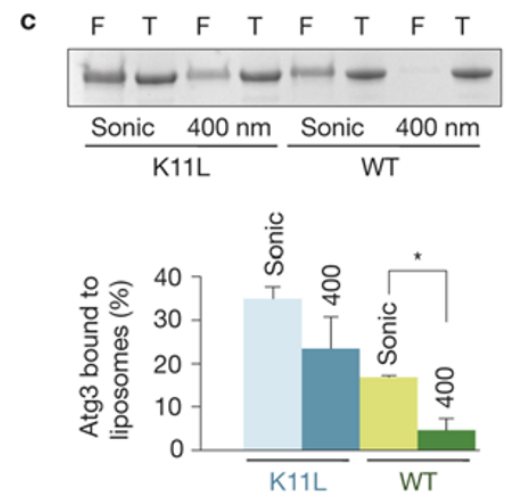

